\title{
Trema micrantha como causa de pneumopatia tóxica em ovinos: reprodução experimental ${ }^{1}$
}

\author{
Flademir Wouters ${ }^{2 *}$, Angelica T.B. Wouters ${ }^{2}$, Veronica M. Rolim² ${ }^{2}$, Mauro Pereira \\ Soares $^{3}$ e David Driemeier ${ }^{2}$
}

\begin{abstract}
Wouters F., Wouters A.T.B., Rolim V.M., Soares M.P. \& Driemeier D. 2013. [Trema micrantha as cause of toxic pneumopathy in sheep: experimental reproduction.] Trema micrantha como causa de pneumopatia tóxica em ovinos: reprodução experimental. Pesquisa Veterinária Brasileira 33(10):1227-1236. Setor de Patologia Veterinária, Faculdade de Veterinária, Universidade Federal do Rio Grande do Sul, Av. Bento Gonçalves 9090, Porto Alegre, RS 91540-000, Brazil. E-mail: flademir@dmv.ufla.br

This paper describes the experimental Trema micrantha poisoning in sheep. Four from five sheep showed marked respiratory distress and death after ingestion of the third dose of plant leaves. The most frequent clinical findings were tachypnea, dyspnea, rhythmic contraction of the nostrils, cyanotic mucous membranes, mucous nasal discharge, hyperthermia, abdominal distension, increased volume and crepitation of parotid region, walking with the legs kept away laterally and sternal recumbency. T. micrantha proved to be toxic to sheep at 20 to $50 \mathrm{~g} / \mathrm{kg}$ bodyweight. At necropsy, we observed cyanotic mucous membranes, subcutaneous emphysema in the ventral area of cervical region or dorsal mediastinum, heavy and collapsed lungs with rib markings, red frothy fluid in the lumen of the trachea and primary bronchi, and several subpleural petechiae. Microscopic examination of lung tissue sections revealed that the tissue was characterized by thickening of the alveolar septa by diffuse type II pneumocytes proliferation, conferring an adenomatous appearance to some areas. These pneumocytes had large and hyperchromatic, sometimes bizarre nucleus or were multinucleate, with evident nucleoli. In some areas desquamated pneumocytes were found in the alveolar lumen, sometimes forming syncytia. There also was bronchiolar epithelium proliferation, conferring to the mucosa more than one epithelial cell layer, these cells had large and hyperchromatic nuclei and reduction in the amount of cilia. The proliferative changes of pneumocytes and bronchiolar epithelium were evaluated by anti-cytokeratin and anti-Ki-67 immunostaining. In order to differentiate pneumocytes and alveolar macrophages, we used anti-monocyte marker (MAC387). One sheep showed clinicopathological findings of acute liver failure with hepatocellular necrosis after ingestion of $25 \mathrm{~g} / \mathrm{kg}$ T. micrantha. The experimental poisoning by T. micrantha in sheep resulted in predominantly respiratory clinicopathological findings, confirming the results of spontaneous poisoning.
\end{abstract}

INDEX TERMS: Poisonous plants, Trema micrantha, diseases of sheep, plant poisoning, lung lesions, immunohistochemistry.

\footnotetext{
${ }^{1}$ Recebido em 30 de agosto de 2013.

Aceito para publicação em 17 de setembro de 2013.

Parte da Tese de Doutorado do primeiro autor.

${ }^{2}$ Departamento de Patologia Clínica Veterinária, Faculdade de Veterinária, Universidade Federal do Rio Grande do Sul (UFRGS), Av. Bento Gonçalves 9090, Porto Alegre, RS 95320-000, Brasil. *Autor para correspondência: flademir@dmv.ufla.br

${ }^{3}$ Laboratório Regional de Diagnóstico, Faculdade de Veterinária, Universidade Federal de Pelotas (UFPel), Campus Universitário s/n, Pelotas, RS 96010-900, Brasil.
}

RESUMO.- A intoxicação experimental por Trema micrantha em cinco ovinos é descrita. Quatro ovinos apresentaram sinais clínicos respiratórios acentuados e morte após ingestão da terceira dose de folhas da planta. As manifestações clínicas mais frequentes nesses casos foram taquipneia, dispneia, retração ritmada das narinas, mucosas cianóticas, corrimento nasal mucoso, hipertermia, aumento de volume abdominal bilateral e na região parotídea, incluindo crepitação à palpação, membros lateralmente afastados ao ca- 
minhar e decúbito esternal. T. micrantha mostrou-se tóxica para ovinos na dose de $20-50 \mathrm{~g} / \mathrm{kg}$ de peso animal. Na necropsia desses ovinos foram observados, além das mucosas cianóticas, enfisema subcutâneo em região cervical ventral ou porção mediastinal dorsal, pulmões não colabados, pesados, com impressão das costelas na superfície e conteúdo espumoso vermelho em traqueia e brônquios, além de múltiplas petéquias subpleurais. $\mathrm{Na}$ avaliação histológica predominaram alterações pulmonares, com espessamento de septos alveolares por proliferação difusa de pneumócitos tipo II, conferindo aspecto adenomatoso a algumas áreas. Os pneumócitos apresentavam núcleo volumoso, hipercromático, ora bizarro ou eram multinucleados, com nucléolos evidentes e, em algumas áreas, os pneumócitos estavam descamados para a luz alveolar, ora formando sincícios. Havia também proliferação do epitélio bronquiolar, com formação de mais de uma camada celular, núcleos hipercromáticos e volumosos e redução na quantidade de cílios. As alterações proliferativas dos pneumócitos e do epitélio bronquiolar foram evidenciadas pela imunomarcação anti-citoqueratina e anti-Ki-67 e, para a diferenciação entre pneumócitos e macrófagos alveolares, foi empregada imuno-histoquímica anti-mieloide/histiócitos (MAC387). Um ovino apresentou quadro clinico-patológico de insuficiência hepática aguda, com necrose hepatocelular acentuada após ingestão de $25 \mathrm{~g} / \mathrm{kg}$ de T. micrantha. A intoxicação experimental por T. micrantha em ovinos resultou em quadro clinico-patológico, predominantemente, respiratório na maioria dos casos, confirmando os resultados observados em casos de intoxicação espontânea.

TERMOS DE INDEXAÇÃO: Plantas tóxicas, Trema micrantha, doença de ovinos, intoxicação por plantas, lesões pulmonares, imuno-histoquímica.

\section{INTRODUÇÃO}

Trema micrantha, popularmente conhecida como grandiúva, crindiúva, pau-pólvora e periquiteira, é uma árvore da Família Cannabaceae, nativa do Brasil, que atinge 5-20m de altura. Ocorre nos estados da Região Sul do Brasil, em Minas Gerais, Goiás e Mato Grosso do Sul. No Brasil, T. micrantha é empregada na recuperação de solos degradados ou após queimadas (Lorenzi 2008). Em pequenas propriedades é utilizada inclusive na alimentação de bovinos e caprinos em épocas de escassez de forragem (Traverso et al. 2003, Gava et al. 2010), pois suas folhas são palatáveis para animais de produção (Riet-Correa et al. 2009). Derrubadas de árvores por ação de podas ou vento constituem importantes fatores de risco nos casos de intoxicação (Riet-Correa et al. 2009, Bandarra et al. 2010).

A toxidez de T. micrantha foi caracterizada em intoxicações experimentais em caprinos (Traverso et al. 2002), equinos (Bandarra et al. 2011), bovinos (Traverso et al. 2004) e coelhos (Traverso et al. 2000). Em caprinos a intoxicação foi induzida com doses a partir de $30 \mathrm{~g} / \mathrm{kg}$ de peso vivo, com sinais clínicos iniciando dois dias após ingestão, caracterizados principalmente por anorexia, tenesmo e sinais de encefalopatia hepática (EH) (Traverso et al. 2002). $\mathrm{Na}$ intoxicação experimental em equinos foram relatados sinais clínicos entre 18 e 96h após o consumo de folhas da planta, evolução clínica de 22-61 h e quadro de insuficiência hepática, incluindo icterícia e sinais de EH (Bandarra et al. 2011). Em bovinos ocorreram sinais clínicos a partir de 16h após ingestão da planta, caracterizados por apatia, anorexia, sialorreia, fraqueza progressiva, coma e morte; sinais de EH foram observados entre 67 e $153 \mathrm{~h}$ após ingestão de T. micrantha (Traverso et al. 2004). Na intoxicação por T. micrantha foi observado que o período entre a ingestão da planta e a morte dos animais é mais longo que para as demais plantas de ação hepatotóxica aguda (Traverso et al. 2002, 2003).

Exames de patologia clínica revelaram, em caprinos (Traverso et al. 2002) e bovinos (Traverso et al. 2004) experimentalmente intoxicados por T. micrantha, hipoglicemia e elevação da atividade sérica de gama-glutamil transferase (GGT) e, em equinos, elevação da GGT, dos níveis séricos de amônia e diminuição da glicemia (Bandarra et al. 2011).

Os achados de necropsia na intoxicação por T. micrantha em caprinos foram caracterizados, principalmente, por hemorragias disseminadas, mais evidentes em tecido subcutâneo e coração e alterações no fígado; que estava amarelado, friável, com evidenciação do padrão lobular (Traverso et al. 2002, 2003, Gava et al. 2010), alteração esta também relatada em equinos intoxicados (Bandarra et al. 2010, 2011). Em bovinos, os achados mais significativos estavam também no fígado, o qual era friável, com evidenciação do padrão lobular e áreas de hemorragia. Havia também petéquias em serosas e edema na parede da vesícula biliar (Traverso et al. 2004).

Como achados histológicos em animais intoxicados por T. micrantha são descritos necrose hepática centrolobular a massiva em caprinos (Traverso et al. 2002, Gava et al. 2010), coelhos (Traverso et al. 2000), bovinos (Traverso et al. 2004) e equinos (Bandarra et al. 2011) e vacuolização de hepatócitos, além de congestão e hemorragia (Traverso et al. 2000, 2002, 2004, Gava et al. 2010, Bandarra et al. 2011). Em equinos havia também tumefação hepatocelular e, em alguns casos, proliferação difusa e acentuada de células epiteliais de ductos biliares, infiltrado de macrófagos e corpúsculos apoptóticos. Alterações encefálicas são também descritas, caracterizadas por degeneração e necrose neuronal, edema perineuronal e perivascular em caprinos (Traverso et al. 2002, Gava et al. 2010) e em bovinos (Traverso et al. 2004); satelitose e vacuolização de substância branca (Gava et al. 2010). No encéfalo de equinos intoxicados são descritos, além de edema perivascular generalizado, astrócitos Alzheimer tipo II na substância cinzenta (Bandarra et al. 2011). Em bovinos o exame histológico revela ainda necrose tubular renal (Traverso et al. 2004).

Recentemente, foi descrita a intoxicação natural por $T$. micrantha em ovinos (Wouters et al. 2013) nos quais observou-se quadro de pneumotoxicidade induzido pela ingestão da planta, não observado na intoxicação em outras espécies animais estudadas, intoxicadas natural ou experimentalmente. Esses achados motivaram a realização do estudo.

Este trabalho tem por objetivos estabelecer a dose tóxica e descrever os achados clinico-patológicos da intoxicação experimental por T micrantha em ovinos. 


\section{MATERIAL E MÉTODOS}

Cinco ovinos mestiços Texel, machos e fêmeas, com 1-2 anos de idade, foram mantidos em baias, em que recebiam feno de alfafa, água potável e sal mineral próprio para ovinos, fornecidos " $a d$ libitum". Os animais foram submetidos a avaliação clínica prévia ao início do experimento, exames parasitológicos de fezes e adaptação por três semanas. Antes da administração da planta os animais foram pesados, avaliados clinicamente e submetidos a colheita de sangue para exames bioquímicos. Folhas de T. micrantha foram colhidas de uma mesma árvore (Fig.1) no município de Porto Alegre e fornecidas no dia da colheita ou esta era realizada no final da tarde, as folhas mantidas refrigeradas e administradas na manhã seguinte. Os animais que não adoeceram após o consumo da primeira dose receberam nova dose 30 dias após e os que não adoeceram receberam uma terceira dose, 30 dias após a segunda. As doses foram ajustadas conforme o desfecho na administração anterior da planta. Um animal (Ovino 1), que adoeceu e se recuperou após a primeira dose, também recebeu mais duas doses, com intervalos de 30 dias. No dia do fornecimento da terceira dose de T. micrantha os Ovinos 1, 4 e 5 foram submetidos a biópsia hepática (percutânea com agulha às cegas) realizada conforme técnica descrita por Néspoli et al. (2010).

Os animais eram submetidos a exame clínico diário, intensificado com o aparecimento de alterações clínicas. Foram realizadas colheitas diárias de amostras de sangue com extração do soro para dosagem de gamaglutamiltransferase (GGT), bilirrubina di-

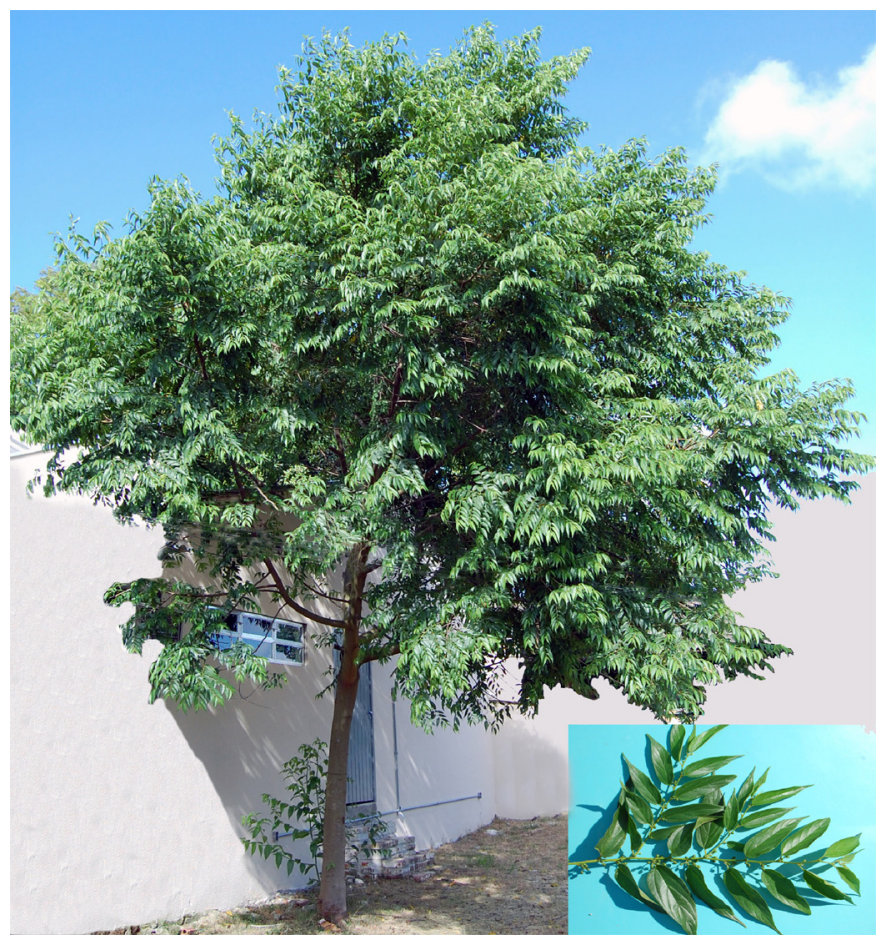

Fig.1. Árvore de Trema micrantha em período vegetativo, Porto Alegre/RS. Em destaque ramo da planta com frutos imaturos.

reta e total. Os animais que não adoeceram e o que se recuperou da primeira administração foram submetidos a colheitas diárias de sangue até 15 dias após a ingestão da planta. Hemograma foi realizado nos animais que apresentaram manifestações respiratórias. Os ovinos foram testados sorologicamente para Maedi-Visna.

Três animais (Ovinos 1, 2 e 3) foram submetidos a eutanásia in extremis. Todos foram necropsiados imediatamente após a morte. Fragmentos de pulmão e fígado de três ovinos (Ovinos 1, 3 e 5) foram fixados em solução tamponada de glutaraldeído a $2 \%$, paraformaldeído a $2 \%$ e cacodilato de sódio, desidratados em etanol e incluídos em resina epoxy para exame de microscopia eletrônica. Cortes semifinos foram corados com azul de metileno. Cortes ultrafinos de áreas selecionadas dos blocos de resina foram contrastados com acetato de uranila e citrato de chumbo. Foi usado microscópio eletrônico de transmissão Zeiss EM 109 a $80 \mathrm{kV}$.

Os pulmões de todos os animais que apresentaram manifestação clínica respiratória foram pesados e colhidos fragmentos para microbiologia. Foram colhidos fragmentos de diversos órgãos e de cada lobo pulmonar de todos os ovinos, acondicionados em frascos individuais e fixados em formalina tamponada $10 \%$. Após a fixação do encéfalo foram efetuados cortes selecionados de telencéfalo, tronco encefálico, cerebelo e medula espinhal. Após a fixação, fragmentos de todos os órgãos foram processados por método histológico de rotina e corados pela técnica da hematoxilina-eosina (HE). Foi realizada a técnica histoquímica de Tricrômico de Masson para evidenciação de proliferação de tecido conjuntivo em pulmões. As técnicas histoquímicas de ácido periódico de Schiff (PAS) e de Perls (Prophet et al. 1992) foram realizadas em fragmentos de fígado de todos os casos.

Fragmentos de pulmão foram submetidos a testes de imuno-histoquímica (IHQ) para evidenciação de pneumócitos tipo II (anticorpo anti-citoqueratina), de macrófagos alveolares (anti-mieloide/histiócitos - MAC387) e de proliferação celular (anti-Ki-67). Detalhes dos protocolos realizados são apresentados no Quadro 1. As lâminas foram incubadas com o anticorpo em câmara úmida overnight a $4^{\circ} \mathrm{C}$. Após a revelação as lâminas foram contracoradas com hematoxilina de Harris por aproximadamente 10 segundos.

Foi realizada, em objetiva 40x, a contagem dos pneumócitos tipo II marcados em 10 alvéolos, aleatoriamente selecionados (imunomarcação anti-citoqueratina); das células epiteliais em proliferação (anti-Ki-67) em 10 bronquíolos e em 10 alvéolos; bem como a contagem dos macrófagos em 10 alvéolos para cada

Quadro 1. Dados dos protocolos das técnicas de imunohistoquímica empregadas na avaliação de pulmões de ovinos experimentalmente intoxicados por Trema micrantha

\begin{tabular}{|c|c|c|c|}
\hline $\begin{array}{l}\text { Anticorpo } \\
\text { Clone }\end{array}$ & $\begin{array}{l}\text { Recuperação } \\
\text { antigênica }\end{array}$ & $\begin{array}{l}\text { Diluição } \\
\text { anticorpo }\end{array}$ & $\begin{array}{l}\text { Método } \\
\text { detecção }\end{array}$ \\
\hline Anti-Citoqueratina & & $1: 80$ & ${\operatorname{Mach~} 4^{c}}^{D^{c}}$ \\
\hline $\begin{array}{l}\text { Anti- Mieloide/ } \\
\text { Histiócitos } \\
\text { Clone MAC } 387^{a}\end{array}$ & $\begin{array}{l}\text { TRIS-EDTA pH } 9.010 \mathrm{~min} \text {, } \\
\text { micro-ondas potência } \\
\text { máxima }\end{array}$ & $1: 300$ & $\begin{array}{c}\text { Mach } 4^{\mathrm{c}} \\
\text { DAB }\end{array}$ \\
\hline $\begin{array}{l}\text { Anti-Ki-67 } \\
\text { Clone MIB-1 }^{\text {a }}\end{array}$ & $\begin{array}{c}\text { Citrato pH } 6.0125^{\circ} \mathrm{C} \\
7 \text { min, panela de pressão }\end{array}$ & $1: 300$ & $\begin{array}{l}\text { Mach } 4^{c} \\
\text { DAB }\end{array}$ \\
\hline
\end{tabular}

a Anticorpo monoclonal anti-humano (Dako), produzido em camundongo; ${ }^{b}$ Protein Block Serum-Free Ready-to-use Dako Code X0909; ${ }^{\text {' Kit }}$ MACH 4 Mouse Probe por 10 minutos e polímero MACH 4 HRP (Biocare Medical, LLC) por 15 minutos; ${ }^{\text {d }}$ Diaminobenzidina (Dako).

caso e calculadas as médias aritméticas. Dois ovinos, cujo óbito não tinha relação com causas tóxicas, infecciosas ou neoplásicas que envolvessem o sistema respiratório foram usados como controle negativo.

\section{RESULTADOS}

Todos os ovinos consumiram a dose fornecida de folhas de T. micrantha, espontaneamente. Todos, exceto o Ovino 2, apresentaram sinais clínicos respiratórios, que iniciaram 5 
a 9 dias após a ingestão da planta, com agravo progressivo. 0 curso clínico variou de 31 a 78 horas, conforme Quadro 2. Foram observados taquipneia, com 60 a 160 movimentos respiratórios/minuto; dispneia, incluindo respiração ruidosa, entrecortada e evidente esforço expiratório; retração ritmada das narinas, além de mucosas conjuntivais e oral ta. 0 Ovino 2 apresentou redução do apetite três dias após ingestão da planta, com progressão para anorexia e atonia ruminal. Permanecia a maior tempo em decúbito esternal, pressionava a cabeça contra paredes da baia ou mantinha a cabeça baixa, apoiada no chão ou no flanco e teve fezes amolecidas poucas horas antes da morte.

\begin{tabular}{|c|c|c|c|c|c|c|c|c|}
\hline $\begin{array}{l}\text { Ovino } \\
\text { no. }\end{array}$ & Sexo & $\begin{array}{l}\text { Idade } \\
\text { (anos) }\end{array}$ & $\begin{array}{c}\text { Administração } \\
\text { da planta }\end{array}$ & $\begin{array}{l}\text { Peso } \\
\text { (kg) }\end{array}$ & $\begin{array}{c}\text { Dose } \\
\text { (g/kg) }\end{array}$ & $\begin{array}{l}\text { Tempo de in- } \\
\text { gestão da planta }\end{array}$ & $\begin{array}{l}\text { Início sinais } \\
\text { clínicos }^{\mathrm{a}}\end{array}$ & Evolução clínica \\
\hline \multirow[t]{3}{*}{1} & $\mathrm{~F}$ & 1 & 1‥ dose & 19,2 & 20 & $1 \mathrm{~h}$ e $30 \mathrm{~min}$ & 9 dias e $9 h$ & Recuperou após 4 dias \\
\hline & & & $2^{\mathrm{a}}$. dose & 20,4 & 22,5 & $1 \mathrm{~h}$ & - & Não adoeceu \\
\hline & & & 3ํ․ dose & 20 & 35 & $13 \mathrm{~h}$ e $45 \mathrm{~min}$ & 5 dias & 78h. Eutanásiab \\
\hline 2 & $\mathrm{~F}$ & 1 & Dose única & 28,2 & 25 & $2 \mathrm{~h}$ & 3 dias & 60h. Eutanásiab \\
\hline \multirow[t]{3}{*}{3} & $\mathrm{~F}$ & 2 & 1ํ․ dose & 26 & 22,5 & $2 \mathrm{~h}$ & - & Não adoeceu \\
\hline & & & $2 \stackrel{\mathrm{a}}{ }$. dose & 27 & 30 & $9 \mathrm{~h} \mathrm{e} 30 \mathrm{~min}$ & - & Não adoeceu \\
\hline & & & $3^{\text {a }}$. dose & 30 & 50 & $17 \mathrm{~h}$ & 9 dias & 31h. Eutanásia ${ }^{b}$ \\
\hline \multirow[t]{3}{*}{4} & M & 1 & 1‥ dose & 32 & 22,5 & $7 \mathrm{~h}$ & - & Não adoeceu \\
\hline & & & $2^{\mathrm{a}}$. dose & 35,3 & 35 & $9 \mathrm{~h} \mathrm{e} 40 \mathrm{~min}$ & - & Não adoeceu \\
\hline & & & $3^{\text {a }}$. dose & 37,7 & 50 & $5 \mathrm{~h}$ & 7 dias e $18 \mathrm{~h}$ & 44h. Morte espontânea \\
\hline \multirow[t]{3}{*}{5} & $\mathrm{~F}$ & 1 & $1^{\mathrm{a}}$. dose & 32,25 & 25 & $4 \mathrm{~h}$ & - & Não adoeceu \\
\hline & & & $2 \stackrel{\mathrm{a}}{\text {. dose }}$ & 34 & 40 & $24 \mathrm{~h}$ e $30 \mathrm{~min}$ & - & Não adoeceu \\
\hline & & & $3^{\text {a }}$. dose & 37,4 & 50 & $14 \mathrm{~h}$ e $30 \mathrm{~min}$ & 6 dias e $7 \mathrm{~h}$ & 43h. Morte espontânea \\
\hline
\end{tabular}

a Após término da ingestão das folhas da planta; ${ }^{\text {b }}$ Realizada in extremis.

cianóticas (Ovinos 1, 3, 4 e 5) e corrimento nasal mucoso discreto (Ovinos 1 e 4). O Ovino 1 apresentava também micção frequente e em pequenos volumes. Elevação da temperatura corpórea $\left(40,7\right.$ a $\left.41^{\circ} \mathrm{C}\right)$ foi constatada em dois animais (Ovinos 3 e 5). 0 Ovino 4 apresentou aumento de volume abdominal bilateral e na região parotídea ventral (Fig.2), com crepitação à palpação. 0 mesmo permanecia em decúbito esternal, no entanto, levantava quando estimulado e mantinha os membros lateralmente afastados ao caminhar.

Os animais mantiveram o apetite, exceto o Ovino 1, que apresentou apetite reduzido e o Ovino 5, com anorexia no último dia do curso clínico. 0 Ovino 1 recuperou o apetite depois de dois dias de manifestação clínica após ingerir a primeira dose da planta, mas apresentou taquipneia por mais 48 horas, com posterior recuperação clínica comple-

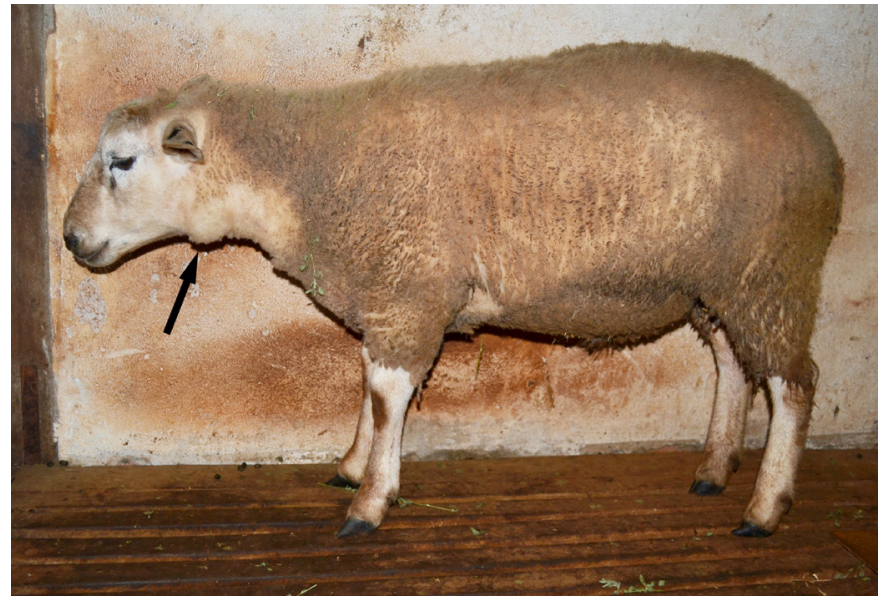

Fig.2. Intoxicação experimental por Trema micrantha (Ovino 5). Acentuada distensão abdominal, aumento de volume na região parotídea (seta) e membros lateralmente afastados.
Os valores séricos de GGT dos ovinos experimentalmente intoxicados são apresentados na Figura 3. Notou-se elevação acentuada dos valores de GGT, com pico de 233,7 U/L no Ovino 2; discreta elevação durante a primeira e a terceira administração no Ovino 1 com pico de 60,2 U/L; e moderada nos Ovinos 3, 4 e 5, com picos de 162,3 , 79,3 e 123,2 U/L, respectivamente, após a terceira administração. Não houve alteração nos valores de bilirrubina total e direta, exceto no Ovino 2 , que apresentou valores máximos $(2,7$ e $1,2 \mathrm{mg} / \mathrm{dL}$, respectivamente $) 6$ dias após ingestão da planta. Todos os animais do experimento foram sorologicamente negativos para Maedi-Visna.

$\mathrm{Na}$ necropsia dos quatro ovinos que apresentaram sinais clínicos respiratórios (Ovinos 1, 3, 4 e 5) foram observados estado corporal regular (Ovinos 1 e 3) ou bom (Ovinos 4 e 5), mucosas conjuntivais e oral discreta (Ovinos 3 e 5) a acentuadamente (Ovinos 1 e 4) cianóticas. No tecido

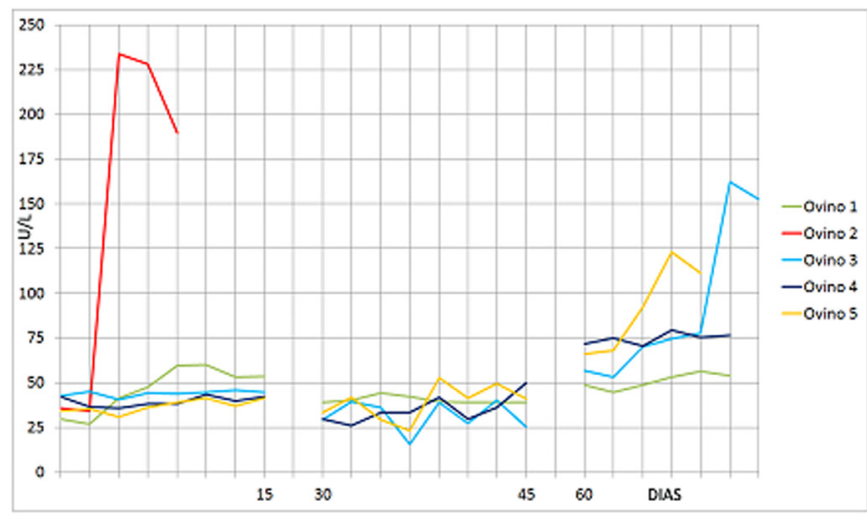

Fig.3. Intoxicação experimental por Trema micrantha em ovinos: valores séricos de gama glutamil transferase (GGT), expressos em U/L, conforme os períodos de administração da planta. 
subcutâneo de dois animais (Ovinos 4 e 5) havia enfisema na região cervical ventral (região parotídea). A cavidade torácica apresentava acúmulo de ar discreto (Ovino 3), moderado (Ovino 4) ou acentuado (Ovino 5) na porção mediastinal dorsal, estendendo-se por todo o mediastino e também na região periférica ao saco pericárdico em um animal (Ovino 5). Os pulmões estavam volumosos, não colabados, com impressão das costelas na superfície, pesados e com aspecto cárneo ao corte (Fig.4) nos quatro ovinos e havia conteúdo espumoso vermelho em brônquios (Ovinos 4 e 5), além de múltiplas petéquias subpleurais. Na traqueia havia pequena quantidade de material mucoso no terço cranial (Ovino 1), mucosa intensamente avermelhada (Ovino 4), conteúdo espumoso vermelho-escuro em toda a extensão (Ovino 4) ou restrito à região da bifurcação tra-
No animal que teve manifestação clínica de insuficiência hepática (Ovino 2) foram observados regular estado corporal, serosas e mucosas discretamente amareladas, mucosas conjuntivais e oral congestas. No fígado havia acentuada evidenciação do padrão lobular, vesícula biliar repleta e, no encéfalo, discreto achatamento das circunvoluções cerebrais.

Na avaliação histológica de quatro animais que apresentaram manifestação clínica respiratória (Ovinos 1, 3, 4 e 5) foram predominantes as alterações pulmonares (Fig.5 e 6), com acentuado espessamento de septos alveolares por proliferação difusa de pneumócitos tipo II, evidenciados pela imunomarcação anti-citoqueratina (Fig.5B), revestindo as paredes alveolares, o que conferia a algumas áreas um aspecto adenomatoso (Fig.6A). Muitos desses pneu-
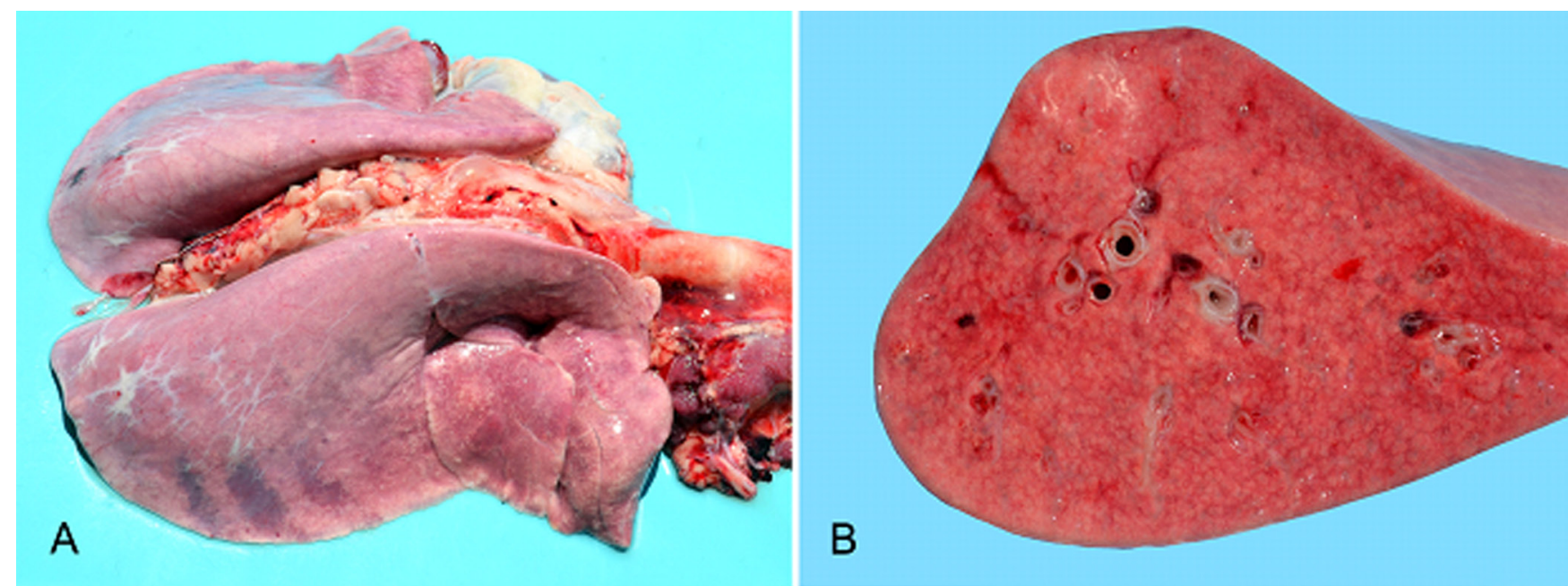

Fig.4. Intoxicação experimental por Trema micrantha (Ovino 3). (A) Pulmões vermelho-arroxeados, volumosos, não colabados, com impressão das costelas na superfície; (B) superfície de corte de A evidenciando aspecto cárneo.

queal (Ovino 5). Peso, textura e coloração dos pulmões são apresentados no Quadro 3.

Pequena quantidade de líquido citrino foi observada no saco pericárdico (Ovino 1) e, no coração (Ovino 5), foram observadas hemorragias subepicárdicas e subendocárdicas multifocais discretas. Ao exame da cavidade abdominal, um animal (Ovino 4) apresentava abundante quantidade de ar livre na cavidade e outro (Ovino 5), enfisema retroperitoneal acentuado. Dois animais (Ovinos 3 e 5) apresentaram também alteração hepática, caracterizada por evidenciação do padrão lobular, principalmente na superfície de corte, além de vesícula biliar repleta.

Quadro 3. Características macroscópicas pulmonares de ovinos experimentalmente intoxicados por Trema micrantha

\begin{tabular}{ccccc}
\hline Ovino & Textura & Coloração & $\begin{array}{c}\text { Peso vivo } \\
\text { kg }\end{array}$ & $\begin{array}{c}\text { Peso pulmões } \\
\text { g }(\%)\end{array}$ \\
\hline 1 & Cárnea & Rósea-escura & 20 & $504,6(2,52 \%)$ \\
2 & Normal & Normal & 28,2 & - \\
3 & Cárnea & Vermelha-arroxeada & 30 & $572(1,91 \%)$ \\
4 & Cárnea & Vermelha-escura & 37,7 & $1.038(2,75 \%)$ \\
5 & Cárnea & Vermelha-escura & 37,4 & $736(1,97 \%)$ \\
Controle 1 & Normal & Normal & 47,5 & $397(0,83 \%)$ \\
Controle 2 & Normal & Normal & 36 & $363(1,01 \%)$
\end{tabular}

mócitos apresentavam núcleo volumoso, hipercromático e nucléolos evidentes, ora bizarros e/ou multinucleados, indicando intensa proliferação celular, confirmada pela imunomarcação anti-Ki-67 (Fig.5C,D). Em algumas áreas havia pneumócitos descamados para a luz alveolar, ora formando sincícios. Havia também proliferação do epitélio bronquiolar, com formação de mais de uma camada celular, núcleos hipercromáticos, volumosos e redução na quantidade de cílios, mais evidente nos Ovinos 3 e 5 . Discreto aumento de tecido conjuntivo foi observado nas paredes alveolares em um caso (Ovino 5), evidenciado pela coloração de Tricrômico de Masson. Havia ainda congestão difusa acentuada, edema difuso acentuado rico em proteína (Ovinos 4 e 5) ou edema difuso discreto (Ovino 3) e formação de membranas hialinas (Ovinos 3, 4 e 5) (Fig.6B). Focos com infiltrado intra-alveolar discreto de neutrófilos foram observados, associados a fibrina (Ovino 4), ou não (Ovino 1) e havia hemorragias multifocais (Ovinos 4 e 5). Na traqueia do Ovino 4 havia congestão difusa acentuada da submucosa. Não houve diferença considerável no tipo e na intensidade das lesões entre os lobos pulmonares avaliados, em nenhum dos animais.

No fígado havia perda significativa de hepatócitos da 


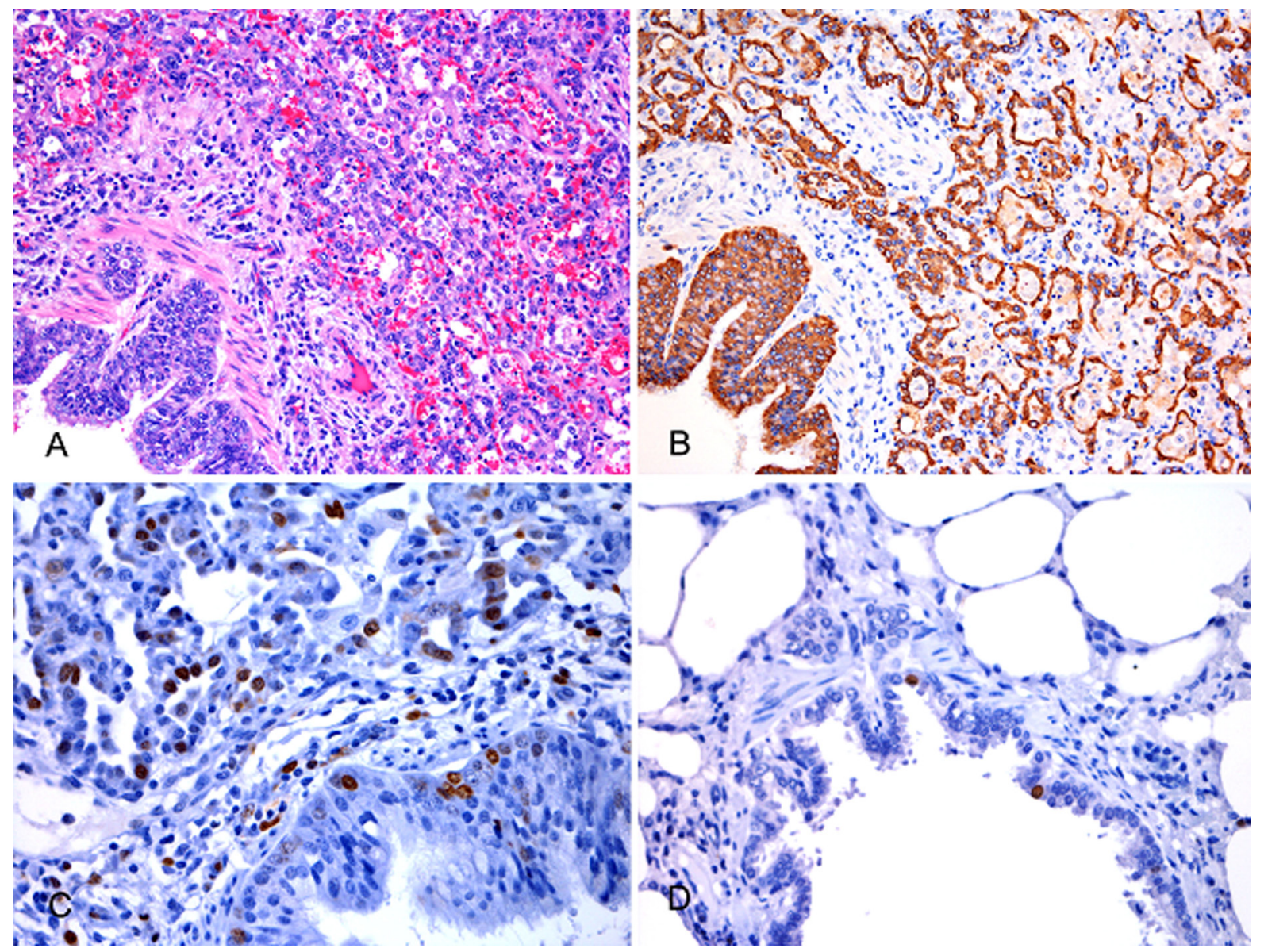

Fig.5. Intoxicação experimental por Trema micrantha. Alterações pulmonares microscópicas. (A) Ovino 5, espessamento de septos alveolares e da mucosa bronquiolar. HE, obj.20x. (B) Ovino 5, imunomarcação anti-citoqueratina evidenciando proliferação de pneumócitos tipo II e do epitélio bronquiolar. Cromógeno DAB, obj.20x. (C) Ovino 3, imunomarcação anti-Ki-67, obj.40x. (D) Ovino controle 2, imunomarcação anti-Ki-67, obj.40x.

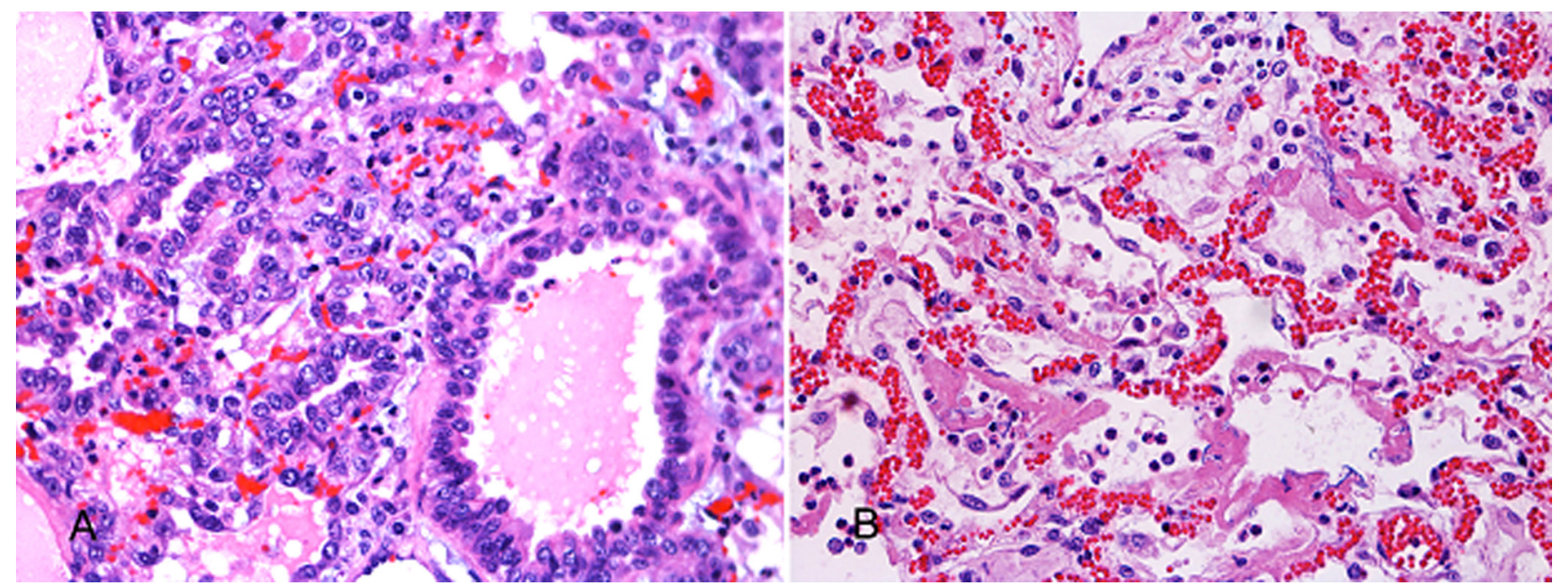

Fig.6. Intoxicação experimental por Trema micrantha. Alterações pulmonares microscópicas. (A) Ovino 5, aspecto adenomatoso devido a proliferação intensa de pneumócitos tipo II, HE, obj.40x. (B) Ovino 4, congestão e edema difusos, formação de membranas hialinas e infiltrado intra-alveolar discreto de neutrófilos. HE, obj.40x.

região centrolobular (Ovinos 1, 3, 4 e 5) associada a sinusoides dilatados e repletos de sangue (Ovinos 3, 4 e 5), necrose individual e apoptose de hepatócitos (Ovino 3) e glóbulos fracamente eosinofílicos em sinusoides da região centrolobular (Ovino 4). Foram observados ocasionais hepatócitos megalocíticos em dois casos (Ovinos 1 e 4), megalocitose moderada (Ovino 5) ou mesmo acentuada (Ovino 3). Havia vacuolização hepatocelular difusa discreta em um 
caso (Ovino 4) ou moderada (Ovinos 1 e 5). Macrófagos com citoplasma repleto de pigmento amarelo-acastanhado granular foram observados em quantidade pequena (Ovino 1), moderada (Ovinos 3 e 4) ou acentuada (Ovino 5); esse material no citoplasma dos macrófagos foi PAS positivo e corou fracamente e de forma granular na técnica de Perls (Ovinos 3 e 5) . No fígado do Ovino 3 havia ocasionais macrófagos hepáticos com citoplasma repleto de restos celulares e/ou hemácias (predominantemente em região centrolobular e ocasionais neutrófilos, além de apresentar na região portal discreta proliferação do epitélio ductal. No fígado do Ovino 1 havia células mesenquimais de núcleo denso e fusiforme, com morfologia sugestiva de células de Ito, as quais tinham vacúolo bem definido no citoplasma.

No exame histológico do Ovino 2 , cujos achados de necropsia eram predominantes no fígado, foram observadas necrose e hemorragia acentuadas centrolobulares a massivas; vacuolização moderada do citoplasma de hepatócitos em área periférica à necrose, além de necrose individual de hepatócitos nesta área. Havia discreta a moderada proliferação do epitélio de ductos biliares, alguns com formação inicial de luz, além de pequena quantidade de neutrófilos, predominantemente em região portal; e alguns macrófagos e células mesenquimais fusiformes a estelares em áreas de necrose e adjacências. Hepatócitos aleatórios apresentavam núcleo volumoso e cromatina esparsa e outros, também ocasionais, tinham pseudoinclusões. No encéfalo desse animal foram observados astrócitos com núcleos amplos e vesiculares em agrupamentos de uma, duas ou três células (astrócitos Alzheimer tipo II) na substância cinzenta do córtex telencefálico frontal, no tálamo, no mesencéfalo (colículo caudal), no óbex, no cerebelo e nos pedúnculos cerebelares. Havia edema na periferia de pericário neuronal na substância cinzenta do córtex telencefálico frontal e edema perivascular, inclusive com material amorfo eosinofílico, tanto na substância cinzenta quanto na branca de telencéfalo e tálamo, porém mais acentuado no córtex telencefálico. Na medula espinhal havia astrócitos com núcleo volumoso, vesicular ou não, na substância cinzenta em intumescência cervical, segmentos cervical, torácico e lombar, além de edema perivascular com material protéico no segmento cervical. Nos rins havia vacuolização moderada do citoplasma do epitélio tubular na junção corticomedular. Nos pulmões desse animal não havia alterações histológicas.

Os achados histológicos das biópsias hepáticas revelaram perda de hepatócitos da região centrolobular com dilatação sinusoidal (Ovinos 3 e 5), ocasional necrose individual de hepatócitos com discreto infiltrado inflamatório misto (Ovino 5) e pequena (Ovino 1) a moderada (Ovinos 3 e 5) quantidade de macrófagos carregados de pigmento amarelo-acastanhado na região centrolobular.

Na técnica de IHQ anti-MAC 387, houve marcação de macrófagos pulmonares, com padrão e intensidade semelhantes entre animais experimentais e controles.

Os valores encontrados nas contagens de pneumócitos

Quadro 4. Quantificação* das células marcadas em pulmões de ovinos experimentalmente intoxicados por Trema micrantha usando imunomarcação anti-citoqueratina (anti-CK B) e de proliferação celular (anti-Ki-67)

\begin{tabular}{ccccc}
\hline Ovino & $\begin{array}{c}\text { Anti-CK B } \\
\text { alvéolos }\end{array}$ & $\begin{array}{c}\text { Anti-Ki-67 } \\
\text { alvéolos }\end{array}$ & $\begin{array}{c}\text { Anti-Ki-67 } \\
\text { bronquíolos }\end{array}$ & $\begin{array}{c}\text { Anti-histiócitos } \\
\text { (MAC 387) }\end{array}$ \\
\hline 1 & 8,6 & 3,6 & 6,1 & 0,3 \\
2 & 1,2 & 0,4 & 0,1 & 0,3 \\
3 & 10,8 & 3,1 & 15,5 & 0,3 \\
4 & 7,0 & 3.0 & 2,7 & 0,4 \\
5 & 10,4 & 4,0 & 7,0 & 0,2 \\
Controle 1 & 1,4 & 0,3 & 0,1 & 0,3 \\
Controle 2 & 0,4 & 0,0 & 0,6 & 0,3
\end{tabular}

* Valores médios obtidos a partir da contagem das células marcadas em 10 estruturas (alvéolos ou bronquíolos) aleatórias.
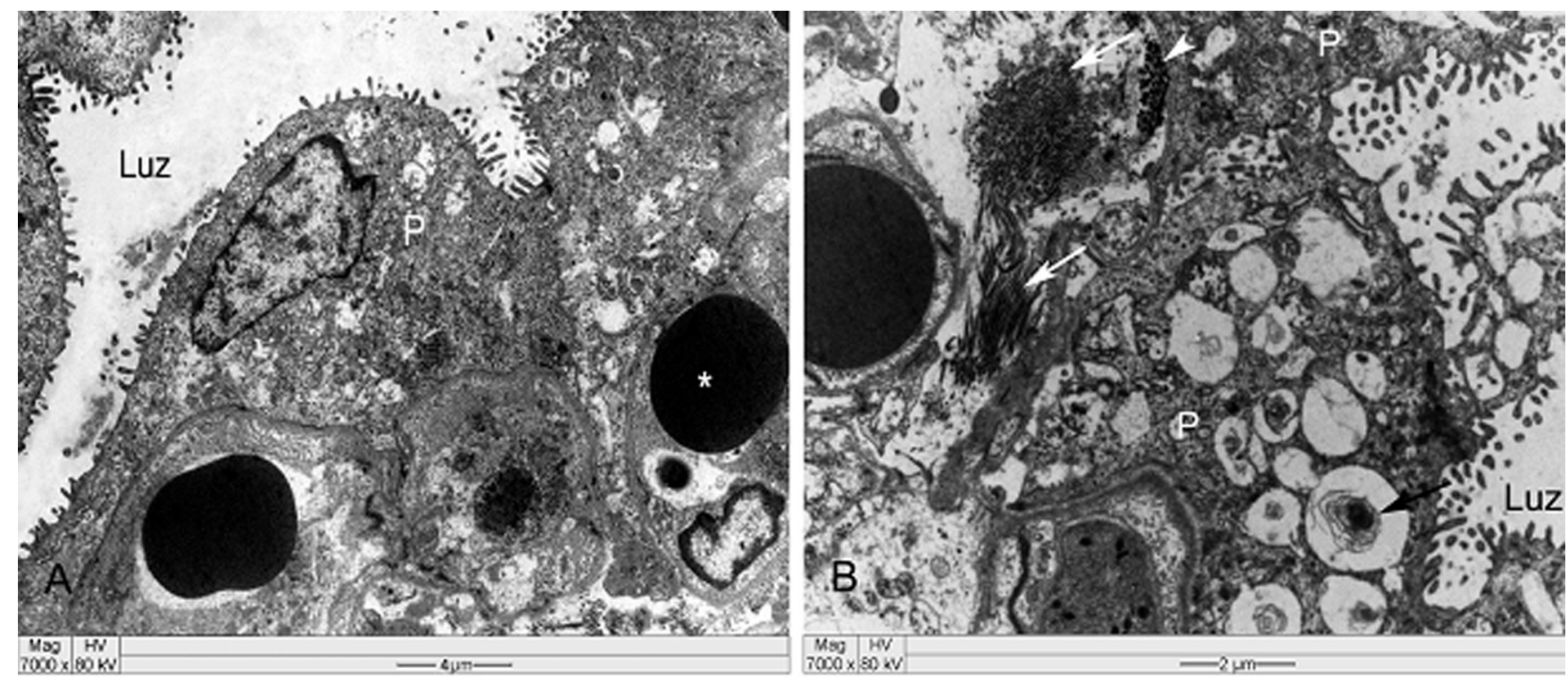

Fig7. Intoxicação experimental por Trema micrantha em ovinos. Microscopia eletrônica do pulmão: (A) pneumócitos do tipo II (P) recobrindo extensas áreas de superfície alveolar, asterisco indica eritrócito no capilar alveolar; (B) pneumócitos com vesículas de secreção e conteúdo escasso (seta) ou totalmente ausente, além de proliferação de fibras colágenas (setas brancas) e elastina (cabeça de seta) formando uma barreira entre a luz alveolar e os capilares. 
tipo II (imunomarcação anti-citoqueratina) e das células epiteliais em proliferação em alvéolos e bronquíolos (anti-Ki-67) são apresentados no Quadro 4.

Os achados dos exames em microscopia eletrônica nos pulmões dos animais avaliados foram semelhantes e consistiam de pneumócitos do tipo I com citoplasma fragmentado, ou sua ausência mantendo, contudo, a lâmina basal intacta. Pneumócitos do tipo II recobriam extensas áreas de superfície alveolar e apresentavam vesículas de secreção com conteúdo escasso ou totalmente ausente, além de proliferação de fibras colágenas e elastina, formando uma barreira entre a luz alveolar e os capilares (Fig.7). No fígado foram observados, em algumas áreas, vários hepatócitos com aumento das cisternas do retículo endoplasmático liso. Em outras áreas, alguns hepatócitos mostravam focos delimitados com aumento das cisternas do retículo endoplasmático liso. Entre algumas das cisternas observaram-se filamentos curtos eletrodensos, além de acentuada tumefação mitocondrial com atrofia acentuada ou destruição das cristas. Na matriz mitocondrial havia conteúdo finamente granular e siderossomos distribuídos pelo citoplasma.

Não foram cultivados agentes bacterianos patogênicos nas amostras pulmonares dos ovinos experimentalmente intoxicados. Os valores hematológicos estavam dentro dos padrões para a espécie.

\section{DISCUSSÃO E CONCLUSÃO}

Dois casos de intoxicação espontânea por Trema micrantha foram diagnosticados em ovinos no Rio Grande do Sul, um deles com quadro clinico-patológico caracterizado por insuficiência hepática com necrose hepatocelular acentuada; o outro por alterações respiratórias graves (Wouters et al. 2013), o que motivou a realização da intoxicação experimental em ovinos.

Mudanças na forma de criar ovinos foram sugeridas como fator predisponente para a intoxicação por plantas na espécie. A ovinocultura, atividade rural tradicional no Rio Grande do Sul, antes exercida em grandes extensões de campo nativo com baixas lotações/hectare e alimentação exclusiva em campo nativo passou a ser exercida também em criações pequenas, com maior densidade animal/área e em regiões sem tradição na criação de ovinos, nas quais podem ser encontradas espécies vegetais potencialmente tóxicas para a espécie (Wouters et al. 2013), justificando a necessidade de caracterização clinico-patológica da intoxicação por T. micrantha em ovinos.

A dose tóxica de T. micrantha para ovinos variou de 20 a $50 \mathrm{~g} / \mathrm{kg}$ de peso vivo. A ingestão de $20 \mathrm{~g} / \mathrm{kg}$ resultou em doença clínica com recuperação posterior; e a menor dose que levou à morte foi de $25 \mathrm{~g} / \mathrm{kg}$, com alterações relacionadas a insuficiência hepática.

A intoxicação por T. micrantha em caprinos (Traverso et al. 2002, 2003, 2005, Gava et al. 2010), equinos (Bandarra et al. 2010, 2011), bovinos (Traverso et al. 2004) e coelhos (Traverso et al. 2000) é caracterizada por insuficiência hepática aguda, com necrose hepatocelular acentuada. Somente em ovinos foi observado quadro clinicopatológico relacionado a alterações pulmonares, observadas em caso natural (Wouters et al. 2013) e reproduzidas experimen- talmente, caracterizado por pneumopatia grave e por um quadro semelhante à síndrome da angústia respiratória aguda (SARA); o achado considerado mais importante da intoxicação por T. micrantha em ovinos. SARA é uma condição clinicamente definida por início agudo, com hipoxemia grave e dano alveolar difuso, além de edema rico em proteínas e formação de membranas hialinas (Caswell \& Williams 2007, López 2012).

0 princípio ativo T. micrantha ainda não está determinado (Matos et al. 2011), no entanto, T. tomentosa, uma árvore semelhante, nativa da Austrália, tem como princípio ativo um glicosídeo denominado trematoxina. A intoxicação por T. tomentosa induz necrose hepatocelular aguda em diferentes espécies animais (Oelrichs 1968).

A intoxicação por alcaloides pirrolizidínicos (AP), presentes em diferentes espécies de plantas, incluindo as crotalárias, cujo efeito mais conhecido está relacionado à hepatotoxidade crônica, pode também induzir lesões pulmonares em diferentes espécies, como suínos (Torres et al. 1997) e equinos (Nobre et al. 2004, Botha et al. 2012). Crotalaria retusa induz hepatopatia tóxica aguda em ovinos, com alterações pulmonares inespecíficas (Nobre et al. 2005).

Alterações pulmonares são relacionadas a várias substâncias pneumotóxicas, como ingestão de batatas-doces (Ipomoea batatas) mofadas contaminadas por Fusarium solani em bovinos (Fighera et al. 2003), banhos por imersão em soluções contendo cresóis em ovinos, provavelmente por absorção cutânea do produto (Linklater et al. 1982). Na África do Sul há descrição de alterações hepáticas agudas e pulmonares em ovinos, relacionada à intoxicação pela planta Hetria pallens (Kellerman et al. 2005).

A doença com morte de ovinos por alterações pulmonares ocorreu apenas após a terceira dose da planta, com aumento progressivo da mesma até atingir 35 a $50 \mathrm{~g} / \mathrm{kg}$. Isso sugere que o aumento progressivo da quantidade de planta ingerida induza resistência parcial à intoxicação. Essa característica é observada em diferentes intoxicações e pode ser explicada por metabolização do princípio ativo pela microbiota ruminal e/ou por detoxificação hepática do mesmo com proliferação do retículo endoplasmático liso (Cullen \& Brown 2012). Foram observados hepatócitos com aumento das cisternas do retículo endoplasmático liso nos ovinos experimentalmente intoxicados por T. micrantha, indicando processo de adaptação celular frente à agressão.

A patogenia da lesão pulmonar induzida pela intoxicação por T. micrantha provavelmente está relacionada à geração de metabólito(s) intermediário(s) que provoca(m) dano ao epitélio alveolar e bronquiolar e, consequentemente, perda da integridade da barreira hematoaérea. Em bovinos, edema e enfisema pulmonar agudo são associados à ingestão de pastagens suculentas ricas em L-triptofano, com produção de 3-metil-indol no rúmen, absorvido e então convertido em produto intermediário eletrofílico altamente pneumotóxico por oxidases de função mista, nas células epiteliais bronquiolares (células de Clara), resultando em peroxidação lipídica e dano a membranas de células bronquiolares e pneumócitos tipo I (Caswell \& Williams 2007, López 2012). 
As alterações pulmonares observadas nos casos de intoxicação por T. micrantha em ovinos, tanto natural (Wouters et al. 2013) quanto experimentais foram caracterizadas por pneumopatia grave com dano alveolar difuso, indicando injúria de pneumócitos tipo I, aumento de permeabilidade vascular, formação de membranas hialinas e proliferação de pneumócitos tipo II. Esta foi evidenciada pela marcação imuno-histoquímica anti-citoqueratina. Como os pneumócitos tipo II, quando avulsos, são indistinguíveis de macrófagos alveolares na coloração de rotina (Caswell \& Williams 2007), foi realizada a técnica de IHQ anti-histiócitos (MAC387) para evidenciação dos macrófagos alveolares. Como não houve diferença no número de células marcadas em relação aos pulmões dos animais controle, foi excluído o aumento na quantidade de macrófagos. Adicionalmente foi observada proliferação de epitélio bronquiolar, caracterizada por múltiplas camadas de células na mucosa bronquiolar e concomitante redução na quantidade de cílios, proliferação essa confirmada pela imunomarcação pelo anticorpo anti-Ki-67. A proteína Ki-67 é expressa nas fases ativas do ciclo celular, com marcação de células em proliferação. A reparação do dano bronquiolar agudo é seguida de esfoliação das células epiteliais para a luz bronquiolar, fagocitose e repopulação por células indiferenciadas e, após vários dias, há diferenciação em células bronquiolares ciliadas normais (López 2012). Proliferação de células não ciliadas (Clara) em bronquíolos terminais foi um achado importante em um surto de intoxicação natural por espécies de Crotalaria em equinos (Botha et al. 2012). Hiperplasia epitelial de pequenos brônquios e bronquíolos é observada na intoxicação por $H$. pallens em ovinos (Kellerman et al. 2005).

A atividade sérica normal da enzima GGT na espécie ovina varia de 20 a $52 \mathrm{U} / \mathrm{L}$ e os teores séricos de bilirrubina total e direta variam de $0,1 \mathrm{a} 0,5 \mathrm{mg} / \mathrm{dL}$ e 0 a $0,27 \mathrm{mg} /$ $\mathrm{dL}$, respectivamente (Radostits et al. 2007). A atividade sérica de GGT dos ovinos experimentalmente intoxicados manteve-se dentro dos padrões de referência nos períodos relacionados à primeira e à segunda administrações, com exceção do Ovino 2, que morreu em decorrência de lesão hepática e apresentou elevação acentuada tanto da GGT, quanto das bilirrubinas e do Ovino 1, que apresentou elevação discreta da GGT no período da primeira administração. Já no período da terceira administração, em que todos os animais morreram ou foram eutanasiados devido a manifestações respiratórias acentuadas, os mesmos apresentaram elevação discreta ou moderada nos valores da GGT, sendo as elevações mais evidentes nos Ovinos 3 e 5, coincidentemente, os animais em que foram evidenciadas alterações hepáticas na necropsia, no entanto não graves o suficiente para induzir manifestações clínicas de insuficiência hepática. Esta observação indica que dosagens séricas de GGT são úteis para identificar dano hepático, mesmo em casos subclínicos.

Dos cinco ovinos experimentalmente intoxicados, quatro apresentaram doença e morte provocadas pelas alterações pulmonares e um apresentou quadro clinico-patológico relacionado à necrose hepatocelular aguda, característica da intoxicação em outras espécies animais, sem manifestação de alterações respiratórias específicas. A diferença na apresentação da doença nos ovinos desse estudo, provavelmente está relacionada principalmente à espécie animal, além da dose de planta ingerida e à suscetibilidade individual.

Enfisema de intensidade variada, observado nas regiões mediastínica, subcutânea ou retroperitoneal, pode ter resultado do aumento anormal da pressão intra-alveolar, causado pelos esforços expiratórios aumentados e pela alteração da permeabilidade entre o espaço aéreo e o interstício. Segundo Caswell \& Williams (2007), o ar pode se estender ao longo dos planos faciais do mediastino e do tecido subcutâneo. 0 exame ultraestrutural dos pulmões dos animais intoxicados demonstrou uma barreira entre a luz alveolar e os capilares, com resultantes alterações significativas nas trocas gasosas.

0 período entre a ingestão da planta e a morte foi consideravelmente mais curto no animal que apresentou quadro clinico-patológico determinado por alterações hepáticas (3 dias) em comparação com os ovinos que apresentaram alterações clínicas e morte por comprometimento pulmonar (8-10 dias).

Os valores hematológicos e do fibrinogênio dos animais experimentalmente intoxicados estavam dentro dos valores de referência para a espécie. Alterações no exame hematológico podem indicar se há infecção viral ou bacteriana; valores elevados em leucograma e concentrações de fibrinogênio sérico são indicativos de quadros infecciosos (Radostits et al. 2007).

Nos exames microbiológicos realizados com as amostras pulmonares dos ovinos intoxicados não foram cultivados agentes bacterianos patogênicos. Pneumonias bacterianas primárias, como pasteurelose pneumônica, ou secundárias a doenças virais como infecção por vírus Parainfluenza-3 podem provocar manifestações clínicas de insuficiência respiratória (Radostits et al. 2007). Adenomatose pulmonar e Maedi-Visna são doenças virais que cursam com alterações respiratórias em ovinos (Driemeier et al. 1998, Moojen \& Riet-Correa 2007), no entanto caracterizam-se por doença crônica com insuficiência respiratória progressiva, diferente do quadro agudo apresentado pelos animais intoxicados por T. micrantha.

Na espécie ovina, o quadro clinico-patológico da intoxicação por T. micrantha é predominantemente caracterizado por alterações respiratórias. Portanto, a intoxicação deve ser considerada como possibilidade diagnóstica em casos de doença do sistema respiratório de ovinos.

Agradecimentos.- Ao Conselho Nacional de Desenvolvimento Científico e Tecnológico (CNPq Proc.478266/2012-0) e à Coordenação de Aperfeiçoamento de Pessoal de Nível Superior (CAPES).

\section{REFERÊNCIAS}

Bandarra P.M., Bezerra Júnior P.S., Oliveira L.G.S., Correa G.L.F., Borba M.R., Reck Júnior J., Cruz C.E.F. \& Driemeier D. 2011. Intoxicação experimental por Trema micrantha (Cannabaceae) em equinos. Pesq. Vet. Bras. 31(11):991-996.

Bandarra P.M., Pavarini S.P., Raymundo D.L., Corrêa A.M.R., Pedroso P.M.O. \& Driemeier D. 2010. Trema micrantha toxicity in horses in Brazil. Eq. Vet. J. 42:456-459. 
Botha C. J., Lewis A., Plessis E.C., Clift S.J. \& Williams M.C. 2012. Crotalariosis equorum ("jaagsiekte") in horses in southern Mozambique, a rare form of pyrrolizidine alkaloid poisoning. J. Vet. Diagn. Invest. 24:1099-1104.

Caswell J.L. \& Williams K.J. 2007. Respiratory system, p.523-653. In: Maxie M.G. (ed). Jubb, Kennedy and Palmer's Pathology of Domestic Animals. Vol.2. $5^{\text {th }}$ Ed. Saunders Elsevier, Philadelphia. 771p.

Cullen J.M. \& Brown D.L. 2012. Hepatobiliary system and exocrine pancreas, p.405-457. In: McGavin M.D. \& Zachary J.F. (Eds), Pathologic Basis of Veterinary Disease. $5^{\text {th }}$ ed. Elsevier Mosby, St Louis. 1322p.

Driemeier D., Moojen V., Faccini G.S. \& Oliveira R.T. 1998. Adenomatose pulmonar ("Jaagsiekte") em ovino no Rio Grande do Sul. Ciência Rural 28:147-150.

Fighera R.A., Rozza D., Piazer J.V., Copetti M.V., Irigoyen L.F. \& Barros C.S.L. 2003. Pneumonia intersticial em bovinos associada à ingestão de batata-doce (Ipomoea batatas) mofada. Pesq. Vet. Bras. 23(4):161-166.

Gava A., Lucioli J., Furlan F.H., Leal M.B. \& Traverso S.D. 2010. Intoxicação por Trema micrantha (Ulmaceae) em caprinos no Estado de Santa Catarina. Pesq. Vet. Bras. 30(3):191-194.

Kellerman T.S., Coetzer J.A.W., Naudé T.W. \& Botha C.J. 2005. Plant poisonings and mycotoxicosis of livestock in Southern Africa. $2^{\text {nd }}$ ed. Oxford University Press, Cape Town. 310p.

Linklater K.A., Angus K.W., Mitchell B., Spence J.A., Rowland A.C. \& Hunter A.R. 1982. Pneumonia in sheep associated with dipping in carbolic dips. Vet. Rec. 110:33-36.

López A. 2012. Respiratory system, mediastinum and pleurae, p. 458-538. In: McGavin M.D. \& Zachary J.F. (Eds) Pathologic Basis of Veterinary Disease. Vol.2. $5^{\text {th }}$ ed. Mosby Elsevier, St Louis.

Lorenzi H. 2008. Árvores brasileiras. Manual de identificação e cultivo de plantas arbóreas nativas do Brasil. Vol.1. $5^{\text {th }}$ ed. Instituto Plantarum, Nova Odessa. 384p.

Matos F.J., Lorenzi H., Dos Santos L.F.L., Matos M.E.O., Silva M.G.V. \& Sousa M.P. 2011. Plantas Tóxicas: estudo de fitotoxicologia, química de plantas brasileiras. Plantarum, São Paulo. 247p.

Néspoli P.B., Gheller V.A., Peixoto P.V., França T.N., Carvalho A.U., Araújo D.K.G. \& Malm C. 2010. Avaliação de técnicas de biópsia hepática em ovinos. Pesq. Vet. Bras. 30(1):29-36.

Nobre V.M.T., Dantas A.F.M., Riet-Correa F., Barbosa Filho J.M., Tabosa I.M. \& Vasconcelos J.S. 2005. Acute intoxication by Crotalaria retusa in sheep. Toxicon 45:347-352.
Nobre V.M.T., Riet-Correa F., Barbosa Filho J.M., Dantas A.F.M., Tabosa I.M. \& Vasconcelos J.S. 2004. Intoxicação por Crotalaria retusa (Fabaceae) em Equídeos no semi-árido da Paraíba. Pesq. Vet. Bras. 24(3):132-143.

Moojen V. \& Riet-Correa F. 2007. Maedi-visna dos ovinos, p.174-179. In: Riet-Correa F., Schild A.L., Lemos R.A.A. \& Borges J.R.J. (Eds), Doenças de Ruminantes e Equídeos. Vol.1. 3aㅡ ed. Pallotti, Santa Maria.

Oelrichs P.B. 1968. Isolation and purification of trema toxin from Trema aspera. Phytochem. 7:1691-1693.

Prophet E.B., Mills B., Arrington J.B. \& Sobin L.H. P992. Laboratory Methods in Histotechnology. American Registry of Pathology, Armed Forces Institute of Pathology, Washington DC. 274p.

Radostits O.M., Gay C.C., Hinchcliff K.W. \& Constable P.D. 2007. Veterinary Medicine. $10^{\text {th }}$ ed. Saunders Elsevier, Edinburgh. 2156p.

Riet-Correa F., Medeiros R.M.T., Pfister J., Schild A.L. \& Dantas A.F.M. 2009. Poisonings by Plants, Mycotoxins and Related Substances in Brazilian Livestock. UFCG, Campina Grande, PB. 246p.

Torres M.B.A.M., Salles M.W.S., Headley S.A. \& Barros C.S.L. 1997. Intoxicação experimental por sementes de Crotalaria spectabilis (Leguminosae) em suínos. Ciência Rural 27(2):307-312.

Traverso S.D., Colodel E.D., Loretti A.P., Correa A.M. \& Driemeier D. 2003. Intoxicação natural por Trema micrantha em caprinos. Ciência Rural 33(1):133-136.

Traverso S.D., Correa A.M., Pescador C.A., Colodel E.D., Cruz C.E.F. \& Driemeier D. 2002. Intoxicação experimental por Trema micrantha (Ulmaceae) em caprinos. Pesq. Vet. Bras. 22(4):141-147.

Traverso S.D., Corrêa A.M.R., Schmitz M., Colodel E.M. \& Driemeier D. 2004. Intoxicação experimental por Trema micrantha (Ulmaceae) em bovinos. Pesq. Vet. Bras. 24(4):211-216.

Traverso S.D. \& Driemeier D. 2000. Experimental Trema micrantha (Ulmaceae) poisoning in rabbits. Vet. Human Toxicol. 42(5):301-302.

Traverso S.D., Zlotowski P., Germer M., Cruz C.E.F. \& Driemeier D. 2005. Spontaneous poisoning by Trema micrantha (Ulmaceae) in goats. Acta Scient. Vet. 33(22):207-210.

Wouters F., Wouters A.T.B., Watanabe T.T.N., Soares M.P., Cruz C.E.F. \& Driemeier D. 2013. Pneumotoxicosis in sheep caused by Trema micrantha poisoning. Vet. Pathol. 00(0):1-4. (Published online before print, Febr. $15,2013)$ 